\title{
BMJ Open AIDS Therapy Evaluation in the Netherlands (ATHENA) national observational HIV cohort: cohort profile
}

\author{
Tamara Sonia Boender, ${ }^{1}$ Colette Smit, ${ }^{1}$ Ard van Sighem, ${ }^{1}$ Daniela Bezemer, ${ }^{1}$ \\ Catriona J Ester, ${ }^{1}$ Sima Zaheri, ${ }^{1}$ Ferdinand W N M Wit, ${ }^{1,2,3}$ Peter Reiss, ${ }^{1,2,3}$ on \\ behalf of the ATHENA national observational HIV cohort
}

To cite: Boender TS, Smit C, Sighem A, et al. AIDS Therapy Evaluation in the Netherlands (ATHENA) national observational HIV cohort: cohort profile. BMJ Open 2018:8:e022516. doi:10.1136/ bmjopen-2018-022516

- Prepublication history for this paper is available online. To view these files, please visit the journal online (http://dx.doi org/10.1136/bmjopen-2018022516).

Received 13 March 2018 Revised 20 June 2018 Accepted 6 August 2018
Check for updates

(C) Author(s) (or their employer(s)) 2018. Re-use permitted under CC BY-NC. No commercial re-use. See rights and permissions. Published by BMJ.

${ }^{1}$ Stichting HIV Monitoring, Amsterdam, the Netherlands ${ }^{2}$ Department of Global Health, Academic Medical Center of the University of Amsterdam, Amsterdam, the Netherlands

${ }^{3}$ Department of Global Health, Amsterdam Institute for Global Health and Development, Amsterdam, the Netherlands

Correspondence to Dr Tamara Sonia Boender; s.boender@amc.uva.nl

\section{ABSTRACT}

Purpose In 1998, the AIDS Therapy Evaluation in the Netherlands (ATHENA) national observational HIV cohort was established to demonstrate the lifesaving effectiveness of triple combination antiretroviral therapy, including HIV-protease inhibitors, that had recently been made available for clinical use. Subsequently, the HIV Monitoring Foundation was established by the Dutch Ministry of Health, Welfare and Sport to continue ATHENA as an open cohort in order to continue the registration and monitoring of all HIV-positive people as an integral part of HIV care in all 26 HIV treatment centres in the Netherlands. Participants To date, a total of 25036 participants have been enrolled in the cohort, with 263600 person-years of follow-up. As of 1 January 2017, 19035 HIV-1-positive participants were known to be in care: 18824 adults $(81 \%$ men and $19 \%$ women) and 211 children (47\% boys and $53 \%$ girls). The remaining 6001 participants had either died $(46 \%)$, were lost to care $(29 \%)$ or had moved abroad (25\%).

Findings to date Today, with over 20 years of follow-up, the ATHENA cohort has provided extensive knowledge on HIV treatment, comorbidities and coinfections and created insight into the transmission dynamics of the HIV epidemic. Future plans ATHENA continues to enrol and monitor HIV positive people entering HIV care in the Netherlands. Future research will continue to provide tangible input into HIV care and prevention policies in the Netherlands and internationally.

\section{INTRODUCTION}

The AIDS Therapy Evaluation in the Netherlands (ATHENA) cohort is a nationwide observational cohort that monitors HIV management of all HIV-positive people in HIV care in the Netherlands, since the introduction of highly active antiretroviral therapy (HAART nowadays known as combination antiretroviral therapy (cART)) when the first HIV-protease inhibitor (PI) became available. As a result of the decisive action taken by the late Dutch Minister of Health, Welfare and Sport, Professor Dr Els Borst, cART including this PI became available in the Netherlands in September 1996. However,

\section{Strengths and limitations of this study}

- The AIDS Therapy Evaluation in the Netherlands (ATHENA) national observational HIV cohort was established in 1998, following the introduction of triple combination antiretroviral therapy (CART) in 1996

- The ATHENA cohort collects clinical data from $98 \%$ of all adults and children in HIV care in the Netherlands ( $2 \%$ opt-out).

- ATHENA is an open cohort, as new participants continue to be enrolled on entry into HIV care, following a positive HIV diagnosis.

- The data are extracted from medical records: the availability of the data depends on the frequency of patient visits and the completeness and detail of the medical record.

- Findings are limited to those observed during follow-up in HIV care.

its swift introduction was conditional on the following: only specialised HIV treatment centres were allowed to prescribe cART, and the effectiveness of cART in clinical practice had to be demonstrated. Accordingly, in November 1997, the Dutch National Health Insurance Council provided a grant to the Academic Medical Center of the University of Amsterdam for the ATHENA cohort to assess the effectiveness of cART in clinical practice. The ATHENA cohort was highly successfully in its mission to 'assess the implications for the course of HIV disease, public health and health care of the introduction of new anti-HIV treatment, the monitoring of that new treatment, as well as the economic costs and benefits of the new treatment'.

Subsequently, in 2000, the Ministry of Health, Welfare and Sport institutionalised the national registration and monitoring of HIV-positive people in care by establishing Stichting HIV Monitoring (SHM; HIV Monitoring Foundation). Under the responsibility of SHM, the ATHENA cohort was continued and extended to all HIV-positive people in 
HIV care in the designated HIV centres (irrespective of the use of cART). Today, the mission of SHM and the ATHENA cohort is to further the knowledge and understanding of all relevant aspects of HIV infection, including comorbidities and coinfections (notably viral hepatitis), in HIV-positive people in outpatient HIV care in the Netherlands.

\section{COHORT DESCRIPTION}

\section{Setting and location}

The ATHENA cohort is an observational, open cohort of all HIV-positive adults and children who enter HIV care in the Netherlands. On 1 November 2000, prior to expansion, the cohort comprised 3449 HIV-positive people, of whom 554 participated in a focus group for substudies on antiretroviral drug resistance and therapeutic drug monitoring, adherence, quality of life and costs of treatment. ${ }^{1}$ The original cohort enrolled people who had died or were otherwise no longer in care, but who had used any of the antiretroviral drugs newly licenced in 1996 or later. Subsequently, the cohort enrolled all HIV-positive people entering HIV care in one of the designated HIV treatment centres for adults and children in the Netherlands (figure 1), including those not yet on cART.

Since November 2005, on the initiative of the Curacao Red Cross Blood Bank, SHM has also assisted in the registration and monitoring of HIV-positive people in care at St. Elisabeth Hospital in Willemstad, Curacao. ${ }^{23}$ Because data collection on Curacao is not part of the ATHENA cohort, this will not be discussed further as it is beyond the scope of this profile.

\section{Eligibility criteria and recruitment}

Registration with SHM and enrolment in ATHENA is an ongoing process. First, all newly diagnosed HIV-positive adults and children entering HIV care are registered at SHM by their treating HIV physician. Subsequently, enrolment in the ATHENA cohort is based on an opt-out principle (see also: Ethical approval and Patient consent). By 1 January 2017, SHM had registered a cumulative number of $25564 \mathrm{HIV}$-positive adults and children in the Netherlands, of whom $525(2.1 \%)$ adults and $3(1.2 \%)$ children opted-out of further data collection ${ }^{4}$ (table 1). Subsequently, a total of $25036(97.9 \%)$ adults and children were enrolled in the cohort with a total follow-up time of 263600 person-years. The majority were HIV-1 positive ( $\mathrm{n}=24 \mathrm{773} ; 98.9 \%)$; the remainder were HIV-2 positive $(\mathrm{n}=97 ; 0.4 \%)$ or had HIV-1 and HIV-2 dual infection $(\mathrm{n}=60 ; 0.2 \%)$ or no serological results $(\mathrm{n}=106 ; 0.4 \%)$.

At initiation, the cohort was approved by the institutional review board of all participating centres. HIV-positive people in care can opt-out after being informed by their treating physician of the purpose of collection of data. Data are pseudonymised before being provided to investigators and may be used for scientific purposes. A designated quality management coordinator safeguards

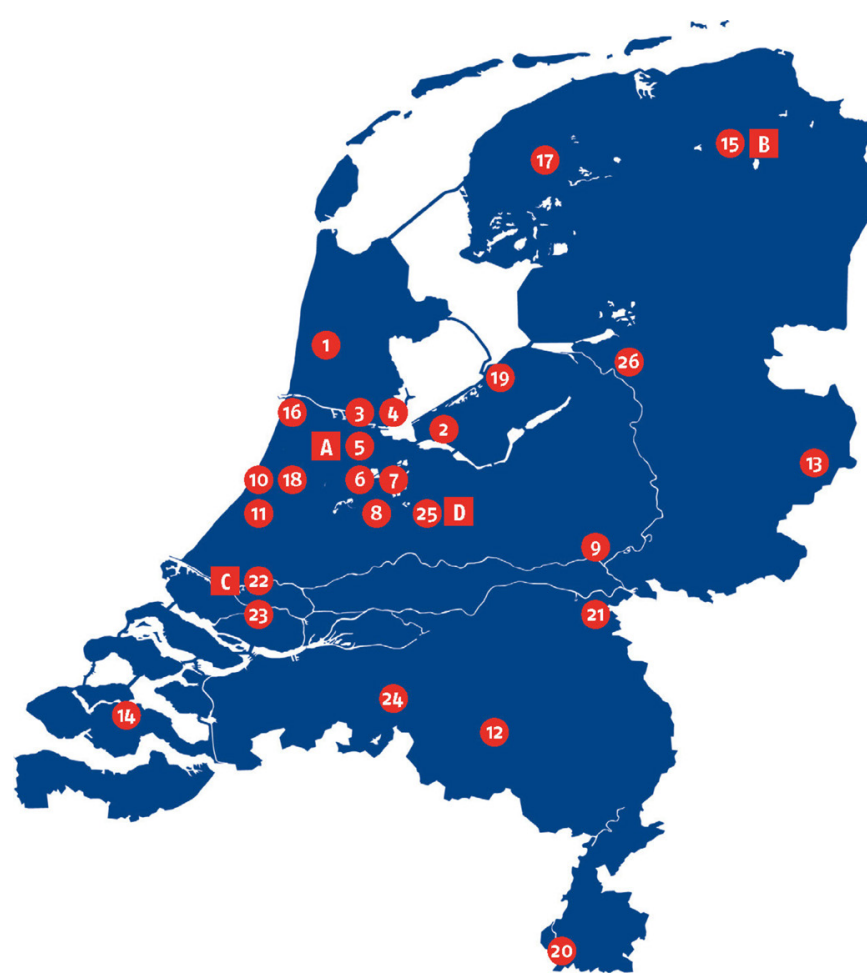

Figure 1 HIV treatment centres in the Netherlands. Legend: adult HIV treatment centres: (1) Noordwest Ziekenhuisgroep, Alkmaar; (2) Flevoziekenhuis, Almere; (3) Academic Medical Center of the University of Amsterdam (AMC-UvA), Amsterdam; (4) DC Klinieken Lairesse - HIV Focus Centrum, Amsterdam; (5) OLVG, Amsterdam; (6) MC Slotervaart, Amsterdam; (7) Medisch Centrum Jan van Goyen (MC Jan van Goyen), Amsterdam; (8) VUmc, Amsterdam; (9) Rijnstate, Arnhem; (10) HagaZiekenhuis (Leyweg site), Den Haag; (11) HMC (Haaglanden Medisch Centrum), Den Haag; (12) Catharina Ziekenhuis, Eindhoven; (13) Medisch Spectrum Twente (MST), Enschede; (14) Admiraal De Ruyter Ziekenhuis, Goes; (15) Universitair Medisch Centrum Groningen (UMCG), Groningen; (16) Spaarne Gasthuis, Haarlem; (17) Medisch Centrum Leeuwarden (MCL), Leeuwarden; (18) Leids Universitair Medisch Centrum (LUMC), Leiden; (19) MC Zuiderzee, Lelystad; (20) Maastricht UMC+ (MUMC+), Maastricht; (21) Radboudumc, Nijmegen; (22) Erasmus MC, Rotterdam; (23) Maasstad Ziekenhuis, Rotterdam; (24) ETZ (Elisabeth-TweeSteden Ziekenhuis), Tilburg; (25) UMC Utrecht (Universitair Medisch Centrum Utrecht), Utrecht; and (26) Isala Zwolle. Paediatric HIV treatment centres: (A) Emma Kinderziekenhuis (EKZ), AMC-UvA, Amsterdam; (B) Beatrix Kinderziekenhuis (BKZ) UMCG, Groningen; (C) Erasmus MC-Sophia Kinderziekenhuis, Rotterdam; and (D) Wilhelmina Kinderziekenhuis (WKZ), UMC Utrecht, Utrecht.

compliance with the European General Data Protection Regulation. $^{5}$

\section{Methods of data collection and follow-up}

Detailed clinical and laboratory data from all enrolled HIV-positive adults and children are extracted from medical records by trained data collectors in cooperation with the responsible HIV-treating physician using an extensive, standardised protocol. In addition, 13 laboratories electronically forward test results directly to SHM. 
Table 1 Registration at SHM and enrolment in the ATHENA cohort: cumulative number of HIV-positive adults and children by 1 January 2017

\begin{tabular}{|c|c|c|c|c|c|c|c|c|c|}
\hline \multirow[b]{2}{*}{ HIV-treatment centre } & \multirow[b]{2}{*}{ Location } & \multicolumn{2}{|l|}{ Total } & \multicolumn{2}{|l|}{ Alive } & \multicolumn{2}{|c|}{ Deceased } & \multicolumn{2}{|c|}{ Opt-out $^{*}$} \\
\hline & & $\mathbf{N}$ & $\%$ & $\mathbf{N}$ & $\%$ & $\mathbf{N}$ & $\%$ & $\mathbf{N}$ & $\%$ \\
\hline \multicolumn{10}{|l|}{ Adults } \\
\hline Noordwest Ziekenhuisgroep & Alkmaar & 360 & 1.4 & 328 & 91.1 & 32 & 8.9 & 5 & 1.4 \\
\hline Flevoziekenhuis & Almere & 200 & 0.8 & 191 & 95.5 & 9 & 4.5 & 3 & 1.5 \\
\hline AMC-UvA & Amsterdam & 3025 & 12.0 & 2608 & 86.2 & 417 & 13.8 & 13 & 0.4 \\
\hline Hiv Focus Centrum & Amsterdam & 597 & 2.4 & 593 & 99.3 & 4 & 0.7 & 0 & 0.0 \\
\hline MC Jan van Goyen & Amsterdam & 312 & 1.2 & 270 & 86.5 & 42 & 13.5 & 4 & 1.3 \\
\hline OLVG & Amsterdam & 3458 & 13.7 & 3042 & 88.0 & 416 & 12.0 & 158 & 4.6 \\
\hline Slotervaart-ziekenhuis & Amsterdam & 860 & 3.4 & 701 & 81.5 & 159 & 18.5 & 12 & 1.4 \\
\hline St Lucas Andreas & Amsterdam & 468 & 1.8 & 417 & 89.1 & 51 & 10.9 & 0 & 0.0 \\
\hline VUmc & Amsterdam & 659 & 2.6 & 569 & 86.3 & 90 & 13.7 & 12 & 1.8 \\
\hline Rijnstate & Arnhem & 850 & 3.4 & 767 & 90.2 & 83 & 9.8 & 3 & 0.4 \\
\hline $\mathrm{HMC}$ & Den Haag & 1108 & 4.4 & 1018 & 91.9 & 90 & 8.1 & 45 & 4.1 \\
\hline HagaZiekenhuis - Leyweg & Den Haag & 756 & 3.0 & 649 & 85.8 & 107 & 14.2 & 32 & 4.2 \\
\hline Catharina Ziekenhuis & Eindhoven & 695 & 2.7 & 649 & 93.4 & 46 & 6.6 & 5 & 0.7 \\
\hline MST & Enschede & 619 & 2.4 & 505 & 81.6 & 114 & 18.4 & 4 & 0.6 \\
\hline Admiraal De Ruyter Ziekenhuis & Goes & 211 & 0.8 & 195 & 92.4 & 16 & 7.6 & 2 & 0.9 \\
\hline UMCG & Groningen & 946 & 3.7 & 846 & 89.4 & 100 & 10.6 & 31 & 3.3 \\
\hline Kennemer Gasthuis & Haarlem & 515 & 2.0 & 459 & 89.1 & 56 & 10.9 & 4 & 0.8 \\
\hline $\mathrm{MCL}$ & Leeuwarden & 310 & 1.2 & 278 & 89.7 & 32 & 10.3 & 1 & 0.3 \\
\hline LUMC & Leiden & 729 & 2.9 & 661 & 90.7 & 68 & 9.3 & 41 & 5.6 \\
\hline MC Zuiderzee & Lelystad & 81 & 0.3 & 80 & 98.8 & 1 & 1.2 & 1 & 1.2 \\
\hline MUMC+ & Maastricht & 934 & 3.7 & 788 & 84.4 & 146 & 15.6 & 5 & 0.5 \\
\hline Radboudumc & Nijmegen & 765 & 3.0 & 675 & 88.2 & 90 & 11.8 & 19 & 2.5 \\
\hline Erasmus MC & Rotterdam & 2636 & 10.4 & 2331 & 88.4 & 305 & 11.6 & 13 & 0.5 \\
\hline Maasstad Ziekenhuis & Rotterdam & 780 & 3.1 & 724 & 92.8 & 56 & 7.2 & 8 & 1.0 \\
\hline ETZ & Tilburg & 1174 & 4.6 & 1093 & 93.1 & 81 & 6.9 & 19 & 1.6 \\
\hline UMC Utrecht & Utrecht & 1749 & 6.9 & 1556 & 89.0 & 193 & 11.0 & 65 & 3.7 \\
\hline Isala - Sophia & Zwolle & 509 & 2.0 & 472 & 92.7 & 37 & 7.3 & 20 & 3.9 \\
\hline Total & & 25306 & 100.0 & 22465 & 88.8 & 2841 & 11.2 & 525 & 2.1 \\
\hline \multicolumn{10}{|l|}{ Paediatric } \\
\hline EKZ, AMC-UvA & Amsterdam & 71 & 27.5 & 71 & 100.0 & 0 & 0.0 & 1 & 1.4 \\
\hline BKZ, UMCG & Groningen & 28 & 10.9 & 28 & 100.0 & 0 & 0.0 & 0 & 0.0 \\
\hline Erasmus MC - Sophia & Rotterdam & 82 & 31.8 & 80 & 97.6 & 2 & 2.4 & 0 & 0.0 \\
\hline WKZ, UMC Utrecht & Utrecht & 77 & 29.8 & 76 & 98.7 & 1 & 1.3 & 2 & 2.6 \\
\hline Total & & 258 & 100.0 & 255 & 98.8 & 3 & 1.2 & 3 & 1.2 \\
\hline
\end{tabular}

*Opt out: never gave permission to collect clinical information.

AMC-UvA, Academic Medical Center of the University of Amsterdam; ATHENA, AIDS Therapy Evaluation in the Netherlands; BKZ, Beatrix Kinderziekenhuis; EKZ, Emma Kinderziekenhuis; ETZ, Elisabeth-TweeSteden Ziekenhuis; HMC, Haaglanden Medisch Centrum; LUMC, Leids Universitair Medisch Centrum; MCL, Medisch Centrum Leeuwarden; MST, Medisch Spectrum Twente; MUMC+, Maastricht UMC+; SHM, Stichting HIV Monitoring; UMCG, Universitair Medisch Centrum Groningen; UMC Utrecht, Universitair Medisch Centrum Utrecht; WKZ, Wilhelmina Kinderziekenhuis.

The ATHENA cohort does not dictate scheduled study visits, examinations or blood work; that is, the frequency and type of visits, examinations and laboratory measurements depend on both the participant and physician.
Consequently, the cohort reflects routine HIV care, and follow-up time in the cohort is equal to follow-up time in HIV care in the Netherlands. If participants move from one HIV treatment centre to another, this transfer 
is registered, and follow-up continues at the new centre. Likewise, children who transfer from paediatric to adult HIV care remain in follow-up. Participant registration and data collection are organised on a national level. When transferring to a new treatment centre within the Netherlands-in case of transfer from paediatric to adult care, or transfer to another treatment centre-the participants' study identifier is retained, and data collection is continued without interruption.

Key epidemiological data are collected from all HIV-positive people on registration at SHM. For national HIV surveillance, SHM reports these statistics to the Centrum voor Infectieziektebestrijding (CIb; Centre for Infectious Disease Control) of the Rijksinstituut voor Volksgezondheid en Milieu (RIVM; National Institute for Public Health and the Environment). Through the RIVM-CIb, SHM also contributes to European HIV surveillance by the European Centre for Disease Prevention and Control (ECDC). ${ }^{6}$

After registration at SHM and enrolment in ATHENA, clinical and laboratory data from all adults and children are prospectively collected as long as the patients remain in care in a Dutch HIV treatment centre. The date of HIV diagnosis is usually retrieved from the letter of referral from the general practitioner or sexually transmitted infections clinic, or from health records in the HIV treatment centre, and can be self-reported on entry to care if there is no documentation available. All reported HIV tests, test dates and test outcomes (including the last negative HIV tests) are captured in the cohort. The data collection process is dynamic and has evolved over the years, with additions and removals of data items based on novel insights and clinical and epidemiological requirements. While the standard data collection protocol is already comprehensive, specific protocols exist for pregnant women, children and hepatitis B (HBV) and hepatitis $\mathrm{C}(\mathrm{HCV})$ virus coinfection. A complete overview of the items that are collected can be found online. ${ }^{7}$

On enrolment, the following information is collected: demographics, history of HIV infection (including the possibility of a primary infection), most likely route of HIV acquisition, smoking, alcohol and drug use. At each visit, the following information is collected: body weight and height, blood pressure, Centers for Disease Control and Prevention classification for HIV infection - Category B (CDC-B) and Centers for Disease Control and Prevention classification for HIV infection - Category C (CDC-C) events, ${ }^{8}$ antiretroviral therapy, adverse events (when resulting in a change of antiretroviral treatment or when specified in the protocol ${ }^{7}$ ), non-AIDS comorbidities (particularly diabetes mellitus, cardiovascular disease, chronic kidney disease and non-AIDS malignancies), comedication and participant's participation in clinical trials or studies. All available laboratory results are collected at each visit: virology, immunology, chemistry, haematology and results on viral coinfections or sexually transmitted diseases. HIV genome sequences and $\mathrm{HCV}$ and HBV genotypes are collected when available.
Furthermore, additional liver diagnostic information (fibroscan, liver pathology and radiology), and additional information concerning HBV and HCV coinfection (HBV vaccination, hepatocellular carcinoma screening, diagnosis and treatment, and virological response to antiviral treatment) are collected. During pregnancy, obstetric and pregnancy-related data are also collected. If applicable, the cause of death is classified by the physician, using the Coding of Death format. ${ }^{9}$

For children, additional information is collected at enrolment and subsequent visits: nationality, country of birth, HIV status of both parents, HIV status of their siblings, perinatal information, head circumference, puberty stage, Centers for Disease Control and Prevention classification for HIV infection - Category A (CDC-A) events, ${ }^{8}$ vaccinations, information regarding psychological, locomotor and puberty development, additional treatment, care and education. Additional laboratory results collected for children comprise HIV DNA and additional viral infections.

\section{Patient and public involvement}

The community of people living with HIV in the Netherlands, represented by the Dutch Association of People Living with HIV (HIV Vereniging), together with healthcare providers and policy makers was closely involved in the establishment and setting-up of the ATHENA cohort in 1997 to monitor the effectiveness of providing early access to life-saving PI containing combination therapy by the Minister of Health. The involvement of the Dutch Association of People Living with HIV continues to the present, with the association being represented on both SHM's Governing Board and Scientific Advisory Board. Findings from the ATHENA cohort are published annually in the HIV Monitoring Report, which is publicly accessible through our website (https://www.hiv-monitoring.nl/english/research/monitoringreports/). Each year, the Dutch Association of People Living with HIV, together with other stakeholders, are asked for input on a press release by SHM in which key findings from the annual report are publicly disseminated.

\section{FINDINGS TO DATE}

Since $2001,{ }^{1}$ the ATHENA cohort provides a comprehensive overview of the trends over time in the HIV epidemic in the Netherlands including the impact of antiretroviral treatment (https://www.hiv-monitoring.nl/english/research/ monitoringreports/). Furthermore, it has advanced our knowledge of HIV-associated comorbidities and coinfections, as well as insight on the spread and prevention of HIV. In addition, a complete and up-to-date list of scientific publications is available online (https://www.hiv-monitoring.nl/english/research/publications/).

\section{Participant characteristics}

On 1 January 2017, 19035 HIV-1-positive participants were known to be in HIV care: 18824 were aged 18 years or older 
and 211 were below 18 years of age (table 2 ). The remaining 6001 participants were no longer in care because they had died $(\mathrm{n}=2776 ; 46 \%)$, were lost to care $(\mathrm{n}=1734 ; 29 \%)$ or had moved abroad $(\mathrm{n}=1491 ; 25 \%){ }^{2}$

\section{The HIV epidemic in the Netherlands}

The ATHENA cohort has generated many insights into the evolution of the Dutch HIV epidemic over time, including information on diagnosed, and estimates of as yet undiagnosed HIV infections, HIV transmission and transmission risk groups. For example, from the 1990s onwards, the annual number of new HIV diagnoses among men who have sex with men (MSM) increased from approximately 400 to well over 800 by 2009 . However, since then, the registered number of new diagnoses has steadily declined, and in 2016, the estimated number of new HIV diagnoses among MSM was 545. Moreover, in the heterosexual population, the number of new diagnoses has declined to between 200 and 250 per year. ${ }^{2}$ Although the overall rate of late presentation has also been declining, ${ }^{10}$ targeted programmes to reduce late HIV diagnoses remain needed for all risk groups and should be prioritised for heterosexual males and females, migrants from South and Southeast Asia and sub-Saharan Africa, people over 50 years of age and certain regions in the Netherlands. ${ }^{11}$

Based on the ATHENA cohort and the ECDC HIV Modelling Tool, ${ }^{12}{ }^{13}$ there were an estimated 1000 new HIV infections each year between 2000 and 2010, which subsequently decreased to 500 in 2016. In MSM, the number of new HIV infections reached a peak of approximately 900 around 2007, and then decreased to approximately 400 in 2016. The estimated number of people living with undiagnosed HIV has also decreased since 2000, although this decrease was less pronounced among MSM. ${ }^{2}$ Studies combining modelling and phylogenetic analysis have shown that HIV transmission among MSM can be averted if men undergo annual HIV testing and, if found to be HIV positive, immediately initiate cART, or, if found to be HIV-negative, half of these men who are perceived to be at high-risk for HIV acquisition initiate pre-exposure antiretroviral prophylaxis. ${ }^{14}$

\section{Response to cART}

In the early 2000s, ATHENA generated additional evidence that cART was efficacious for the treatment of HIV and provided insight into $\mathrm{CD} 4$ cell count and viral load dynamics in both treated and untreated HIV infection. ${ }^{15-17}$ In recent years, initiation of cART following an HIV diagnosis has been taking place increasingly earlier and irrespective of CD4 cell count. By 2016, the median CD4 cell count at start of cART had increased to 410 cells $/ \mathrm{mm}^{3}$, and the majority of people starting cART did so within 1 month of diagnosis (figure 2). At the same time, the time spent on a first-line regimen is increasing, and both short-term and long-term virological suppression rates are high and continue to improve. Since 2000, the annual proportion of individuals on cART with a viral load $>200$ copies $/ \mathrm{mL}$ has decreased to approximately $3 \%$. Consequently, earlier diagnosis in combination with immediate treatment and very low rates of virological failure on treatment have contributed to a substantial decrease in the annual number of new HIV diagnoses among MSM in the Netherlands, despite an increase in risk behaviour. ${ }^{18} 19$

Among adults who do experience virological failure, the rate of acquired drug resistance remains low and continues to decline over time. ${ }^{20}$ The overall prevalence of transmitted resistance remains low over time, in line with European surveillance data. ${ }^{21}$

\section{Trends in morbidity and mortality over time}

Since cART became available, AIDS-related deaths have decreased dramatically and life-expectancy has improved substantially. ${ }^{22}{ }^{23}$ Moreover, data from the cohort led to the Netherlands becoming one of the first countries where HIV-positive people could get life insurance. ${ }^{24}$ The limited and decreasing number of individuals who still die of AIDS each year mainly consist of those presenting late for care.

As a result of both increased life expectancy in people living with HIV, as well as an increase in age at HIV diagnosis, the HIV-positive population in the Netherlands is ageing (figure 3). Modelling studies have provided insight into the expected disease burden resulting from this age shift. By 2030, an estimated 73\% of the HIV-positive population in the Netherlands will be aged 50 years or older, and $84 \%$ of HIV-positive people are expected to have at least one non-communicable disease (up from $29 \%$ in 2010). ${ }^{25}$ Consequently, the annual cardiovascular disease incidence and costs are predicted to increase between 2015 and 2030. However, traditional cardiovascular disease prevention interventions can optimise cardiovascular health and avert future costs, particularly if targeting high-risk individuals. ${ }^{26}$

\section{Continuum of care}

The Netherlands is well on its way to reaching the UNAIDS 90-90-90 targets for 2020, ${ }^{27}$ and Amsterdam is among the first cities to have reached and exceeded these targets. ${ }^{28}$ In 2016, an estimated $89 \%$ of all people living with HIV in the Netherlands were diagnosed and linked to care, $92 \%$ of these people were on cART and $95 \%$ of those on cART had a suppressed viral load (figure 4). Although time from acquiring HIV to reaching viral suppression has declined over time, further decline continues to be challenged mainly by the duration of undiagnosed HIV infection. ${ }^{29}$

\section{Pregnant women, children and adolescents}

The combination of opt-out HIV screening and use of cART in HIV-positive pregnant women has reduced the risk of mother-to-child transmission to $<1 \%$ in the Netherlands. ${ }^{2}$ At the same time, an increasing number of children who acquired HIV through vertical transmission are being adopted from sub-Saharan Africa by Dutch parents. In general, paediatric HIV care has resulted in favourable treatment outcomes, and viral suppression among children has improved substantially over time. ${ }^{30}$ Of note, however, is that adolescents and young adults are particularly vulnerable to virological failure, especially around and shortly 
乡 œ

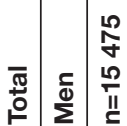

$\stackrel{2}{\stackrel{2}{2}}$

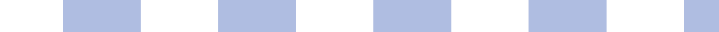

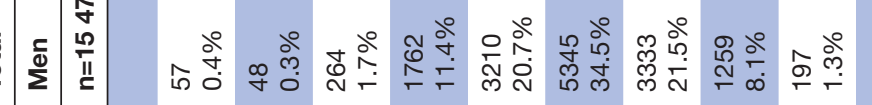

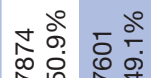

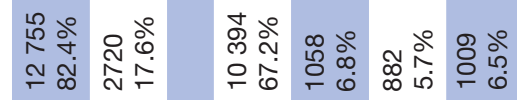

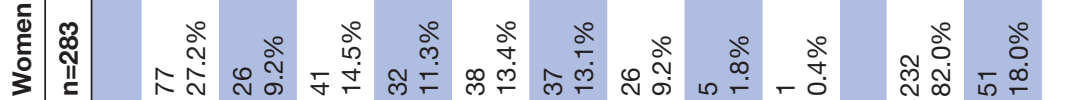

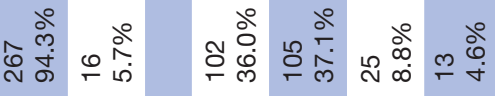

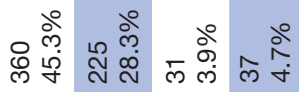

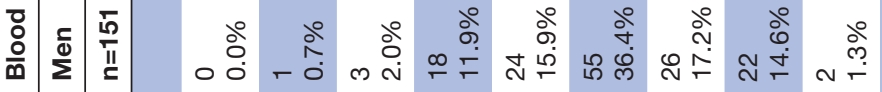

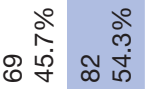

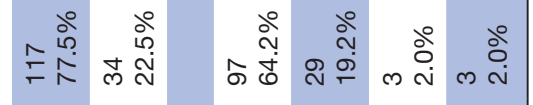

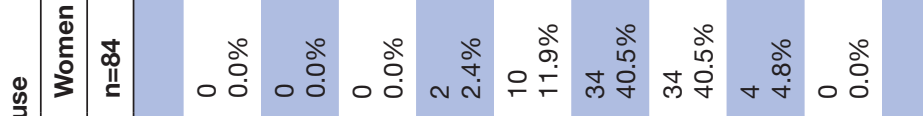

ᄃ

œ

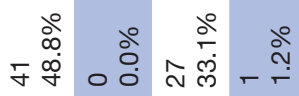

至

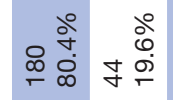

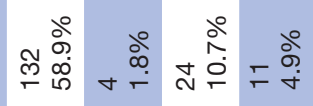

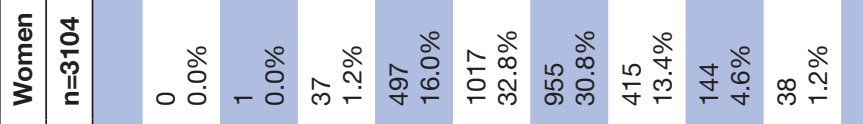

œ̊ำ

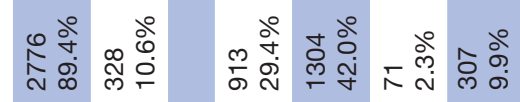

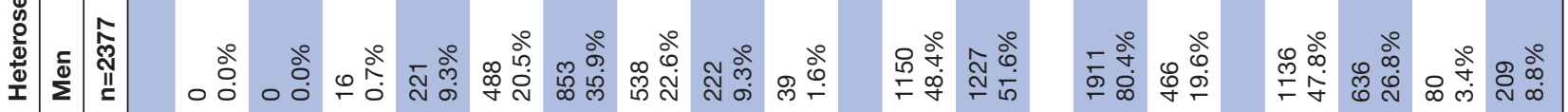




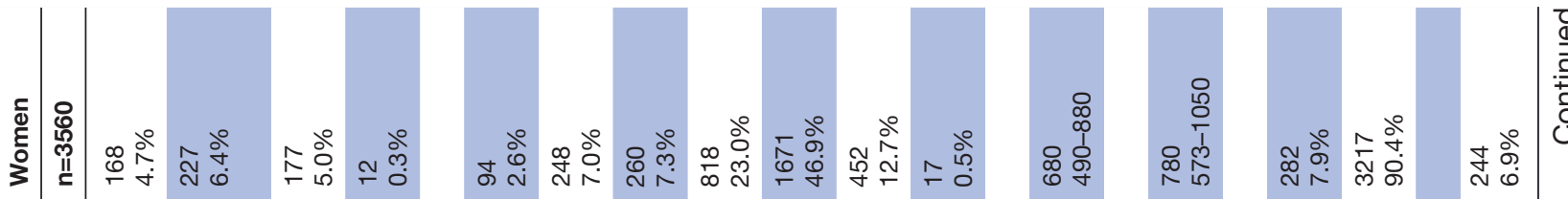

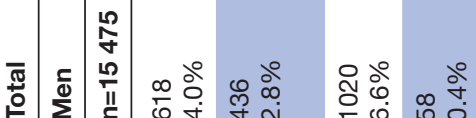

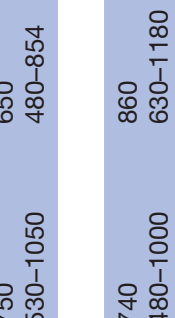

离

ํํำ

全

章

紊

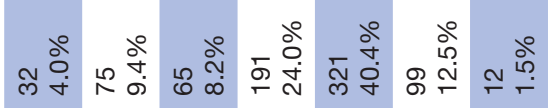

옹

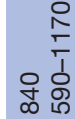

స

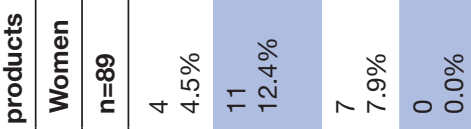

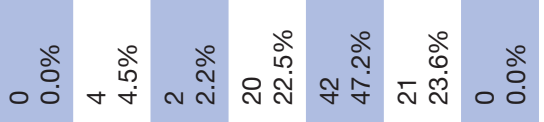

1
0
0
0
1
0

总

$\infty \stackrel{\circ}{\circ} \stackrel{\circ}{\circ} \stackrel{\circ}{\circ}$

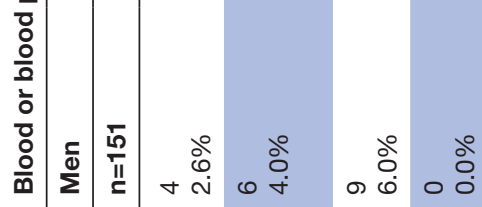

ڤㄴ

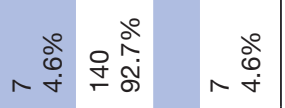

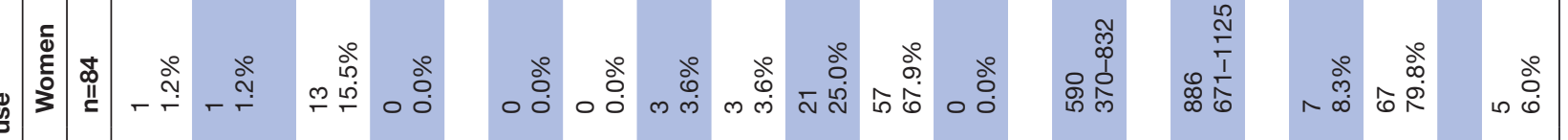

공

至

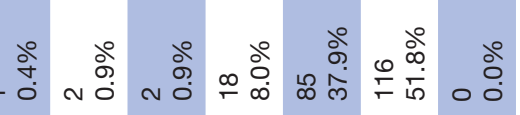

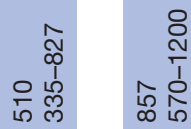

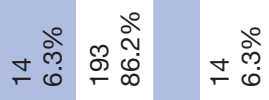

至

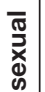

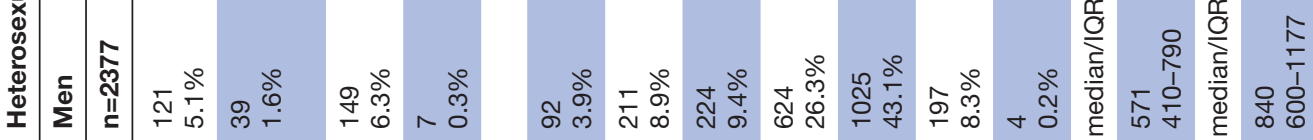

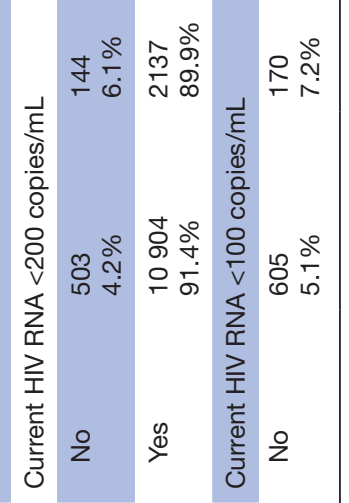

ஸि 


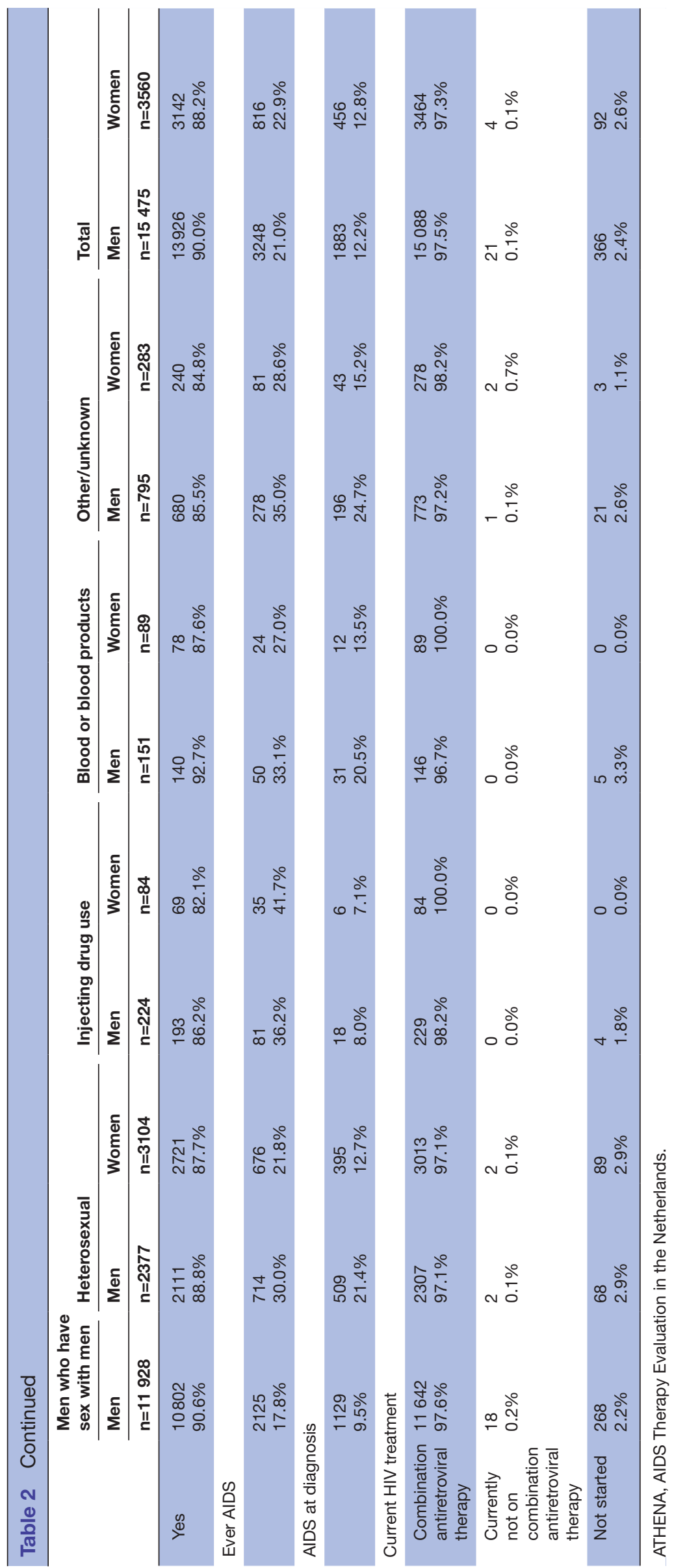

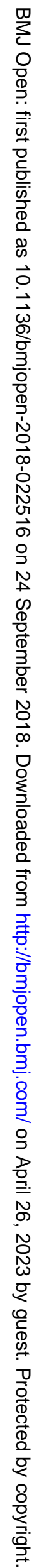




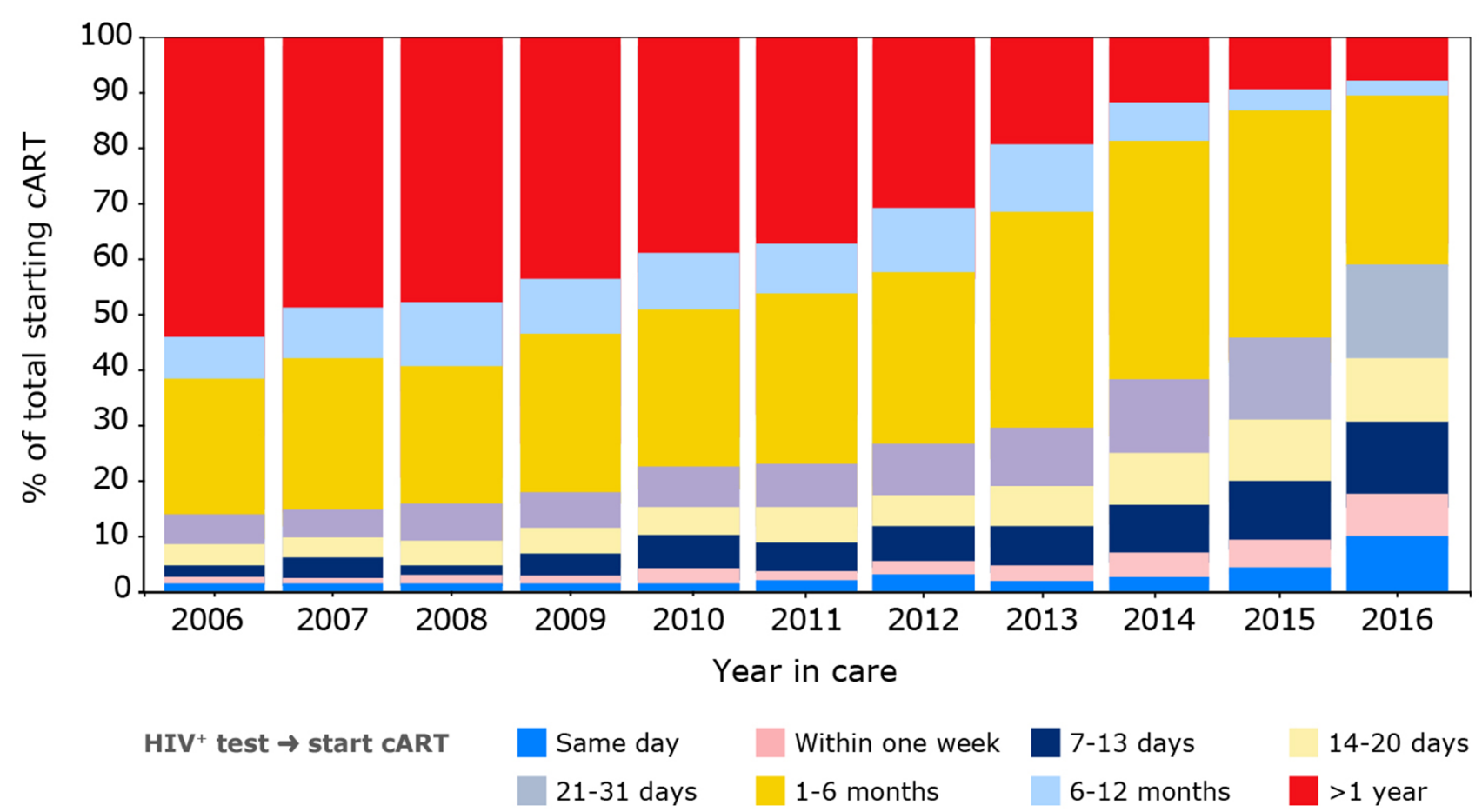

Figure 2 Time between HIV diagnosis and initiation of combination antiretroviral therapy (cART) among people initiating cART by year of entry into care.

after the moment of transition from paediatric to adult care. $^{31}$

\section{Viral hepatitis coinfection}

HBV and HCV coinfections are relatively common among HIV-positive people and are closely monitored in the cohort. $^{2}$ However, phylogenetic analysis has shown limited overlap between HCV and HIV transmission networks,

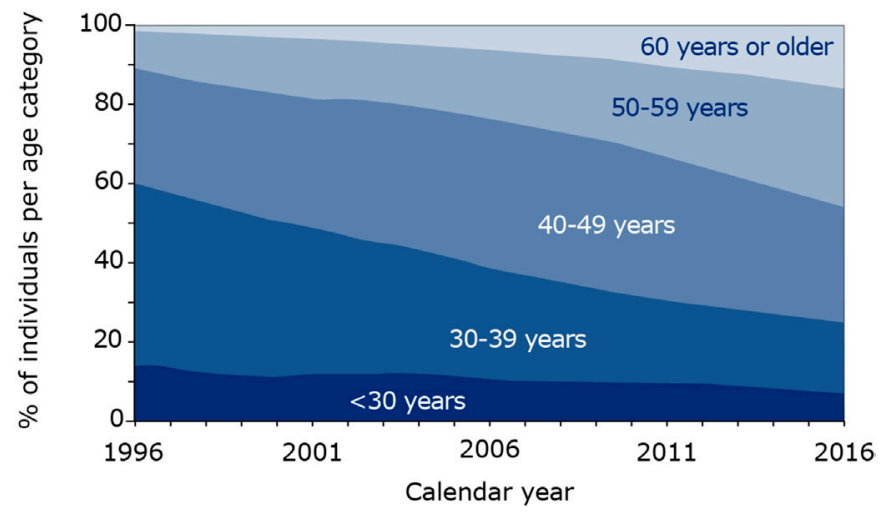

Figure 3 Increasing age distribution of the ATHENA cohort over time. Legend: this figure includes all HIV-1-positive people in clinical care. In 1996, $14 \%$ of the patients in care were younger than 30 years of age, whereas $11 \%$ were 50 years or older. In 2016, these proportions were $7 \%$ and $46 \%$, respectively, while $16 \%$ of patients in care were 60 years of age or older. The proportion of patients in clinical care as of 31 December of each calendar year is shown according to those who were $<30$ years of age, 30-39 years, 40-49 years, 50-59 years and 60 years or older. ATHENA, AIDS Therapy Evaluation in the Netherlands. which indicates a dynamic sexual network structure of Dutch HIV-positive MSM. $^{32}$

Up to 2016, an increase in the prevalence of active HCV (presence of detectable HCV RNA) was reported, especially among MSM. Since the introduction and reimbursement of direct-acting antiviral agents for HCV treatment in 2014, increasing numbers of HIV-positive people with both acute and chronic HCV coinfection have been treated for, and successfully cured of, HCV (ie, sustained virological response) (figure 5). ${ }^{23}$ This has resulted in a rapidly declining number of coinfected individuals in HIV care who still need to be cured of HCV.

\section{STRENGTHS AND LIMITATIONS}

The unique strength of the cohort is its completeness, both in terms of coverage (ie, $98 \%$ of all HIV-positive people in care in the Netherlands), as well as the quality and extensiveness of the data collection. ${ }^{34}$ Furthermore, follow-up and data collection continues uninterrupted for children who transfer from paediatric to adult HIV care and for people who transfer to another HIV treatment centre within the Netherlands.

To improve data quality, SHM has developed a quality management system based on the principals of a plan-docheck-adjust cycle. New data collectors receive intensive training and follow a personal coaching programme. SHM also has an internal helpdesk that resolves questions from the data collectors. After collection, the data are automatically checked for inconsistencies and source-verified by the data management and quality control departments. 


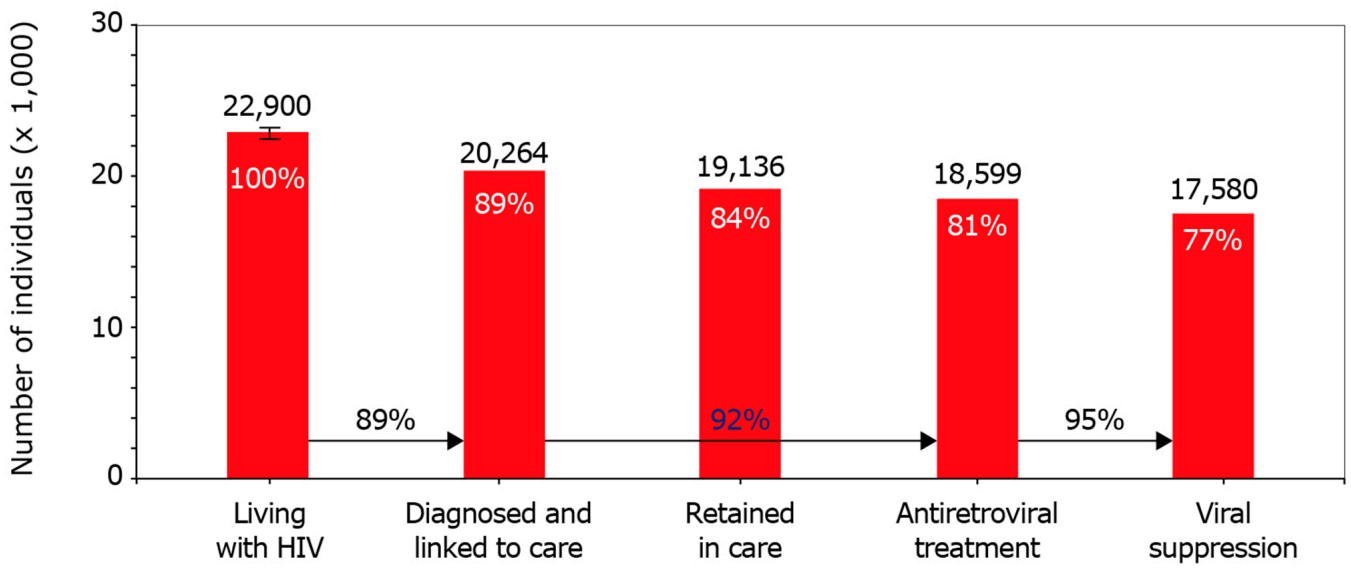

Figure 4 Continuum of HIV care for the total estimated HIV-positive population in the Netherlands in 2016.

SHM has become an integral part of HIV care and works closely with all the HIV-treating physicians and the Nederlandse Vereniging van HIV Behandelaren (Dutch Association of HIV-Treating Physicians). Additionally, SHM has contributed to the development of care indicators and provides these statistics for the Zichtbare Zorg (Visible Care) programme, ${ }^{35}$ which is run by the Public Health Inspection Agency and was commissioned by the Ministry of
Health, Welfare and Sport to allow comparison of quality of healthcare.

Another main strength is the participation of SHM and the ATHENA cohort in regional, national and international scientific research collaborations. There is close collaboration with the Academic Medical Center of the University of Amsterdam, the Public Health Service Amsterdam through the Amsterdam Cohort Studies

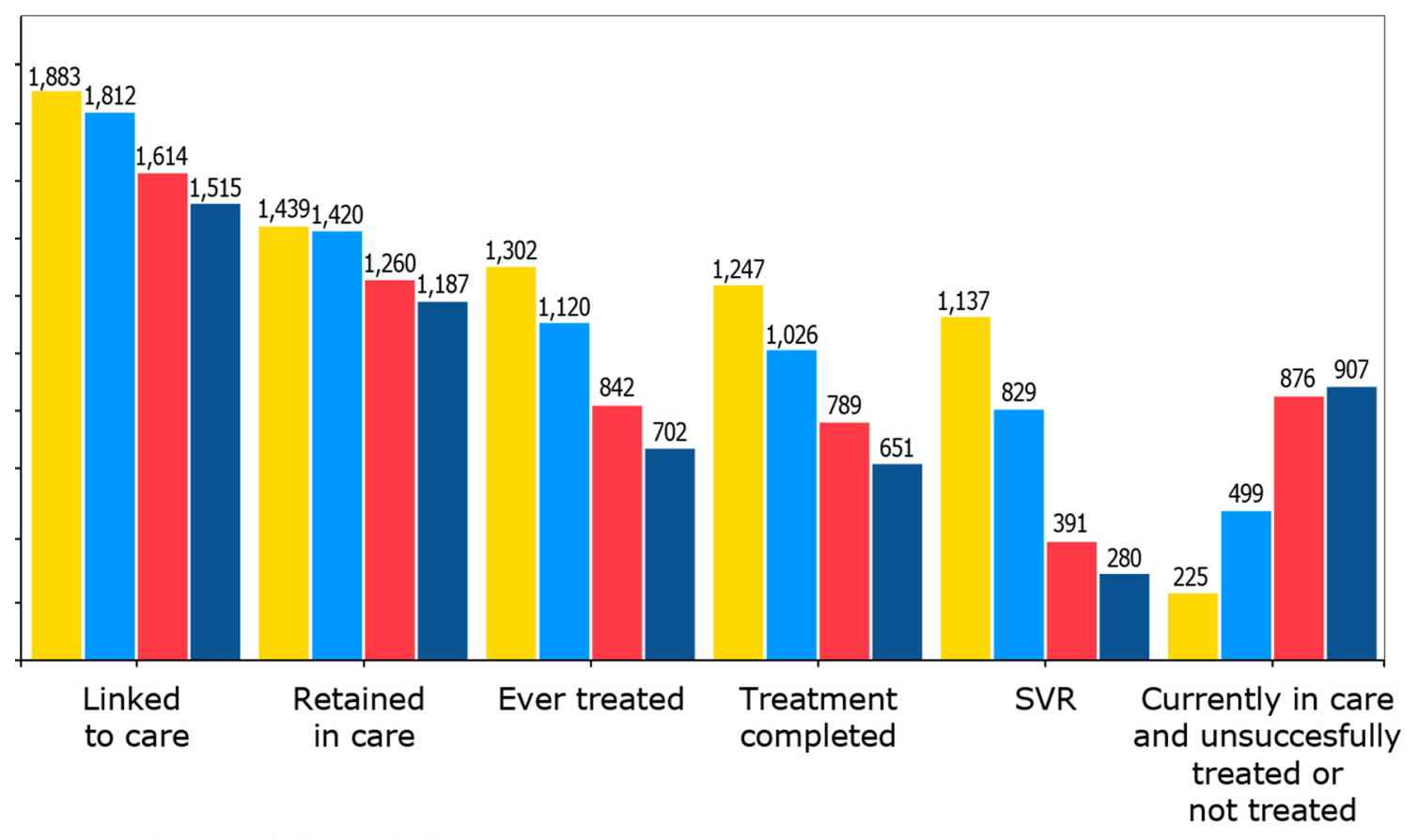

2017 2016

2015

2014

Figure 5 Hepatitis C continuum of care. Legend: out of a total of 1883 individuals linked to HIV care and diagnosed with HCV, 1439 individuals (76\%) were retained in care, and of these 1439, 1302 (90\%) had ever received treatment for HCV. Of the 1302 individuals treated for HCV, 1247 (96\%) had completed HCV treatment and had data available to calculate their HCV treatment response. Overall, 1137 of the 1247 (91\%) individuals who completed treatment had achieved an SVR. As a result, 302 of the 1439 individuals (21\%) who were alive and in care as of 1 May 2017 in one of the Dutch HIV treatment centres remained untreated $(n=137)$, not successfully treated $(n=85)$, were still being treated or had insufficient time after treatment discontinuation to allow SVR calculation $(n=80)$. All 80 individuals in whom SVR could not yet be calculated due to insufficient time since treatment discontinuation had been treated with novel direct-acting antiviral agents combinations. For that reason, we extrapolated the observed direct-acting antiviral agents SVR rate of $97 \%$ and assumed that $97 \%$ of these 80 individuals ( $n=77$ ) will eventually be successfully treated. This resulted in an estimated number of $302-77=225$ individuals who remain untreated or unsuccessfully treated. SVR, sustained virological response (ie, HCV cure). 
$(\mathrm{ACS})^{36}$; the MSM Observational Study of Acute Infection with Hepatitis C (MOSAIC) ${ }^{32}$; Co-morbidity and Ageing with HIV $\left(\mathrm{AGE}_{\mathrm{h}} \mathrm{IV}\right)$ cohort study ${ }^{37}$; EU-funded Co-morbidity in Relation to AIDS (COBRA) programme ${ }^{38}$; and the HIV Transmission Elimination Amsterdam (H-TEAM) initiative. ${ }^{39}$ ATHENA collaborates with other research groups and observational cohorts in western Europe, the USA and Canada. Data sharing and collaboration has taken place or is ongoing with the Collaboration of Observational HIV Epidemiological Research Europe (COHERE) ${ }^{40}$ EuroSIDA, ${ }^{41}$ the European Pregnancy and Paediatric HIV Cohort Collaboration (EPPICC $)^{42}$ within the Paediatric European Network for the Treatment of AIDS (PENTA), the European Coordinating Committee for the Integration of Ongoing Coordination Actions Related to Clinical and Epidemiological HIV Research (EuroCoord); A Collaboration on HIV-2 infection $\left(\mathrm{ACHI}_{\mathrm{E}} \mathrm{V}_{2 \mathrm{E}}\right)^{43}$; Antiretroviral Therapy Cohort Collaboration (ART-CG) ${ }^{44}$; Data collection on Adverse events of anti-HIV Drugs (D:A:D) ${ }^{45}$; HIV Cohorts Analysed Using Structural Approaches to Longitudinal data (HIV-CAUSAL) Collaboration ${ }^{46}$; Bridging the Evolution and Epidemiology of HIV in Europe (BEEHIVE) ${ }^{47}$; HIV Resistance Response Database Initiative (RDI $)^{48}{ }^{49}$; and International epidemiology Databases to Evaluate AIDS (IeDEA)..$^{50}$

A limitation of the cohort is that the data are based on medical records and not on scheduled data collection through questionnaires. While the data collection protocol is structured, the availability of the data depends on the frequency of patient visits and the completeness and detail of the notes in the medical record. Although this provides insight into routine HIV care in a 'real life' setting, some aspects of HIV care and disease progression might go unmeasured and therefore unnoticed. Data collection largely depends on information captured by the medical records of HIV physicians and HIV nurse consultants. This potentially limits obtaining more detailed data regarding less severe comorbid conditions and substance use, which may not be brought to the attention of the HIV physician. Furthermore, while the cohort captures $98 \%$ of all people in HIV care, we do not know well which (eg, migrants) and how many people do not enter HIV care. Another limitation is that HIV genotype sequence data are incomplete and not available from all cohort participants.

\section{COLLABORATION}

HIV physicians can review the data of their own treatment centre and compare these data with the full cohort through an online report builder. Statistical information or data for own research purposes can be requested by submitting a research proposal (https:// www.hiv-monitoring.nl/english/research/researchprojects/). For correspondence: hiv.monitoring@amc. uva.nl.
Acknowledgements The ATHENA national observational HIV cohort is not possible without the ongoing contribution of all HIV treating physicians, nurse consultants and staff at the diagnostic laboratories and facilities in the HIV treatment centres, along with the data collecting and monitoring staff both within and outside Stichting HIV Monitoring (listed under collaborators). We would like to extend our sincerest thanks and appreciation to representatives of the Dutch Association of People Living with HIV (HIV Vereniging) for being represented on SHM's Governing Board and Scientific Advisory Board.

Collaborators CLINICAL CENTRES * denotes site coordinating physician Amsterdam UMC, AMC site, Amsterdam: HIV treating physicians: M. van der Valk * S.E. Geerlings, M.H. Godfried, A.Goorhuis, J.W. Hovius, T.W. Kuijpers, F.J.B. Nellen, D. Pajkrt, T. van derPoll, J.M. Prins, P. Reiss, H.J.Scherpbier, M. van Vugt, W.J. Wiersinga, F.W.M.N. Wit. HIV nurse consultants: M. van Duinen, J. van Eden, A.M.H. van Hes, F.J.J. Pijnappel , A.M. Weijsenfeld. HIV clinical virologists/chemists: S. Jurriaans,N.K.T. Back, H.L. Zaaijer, B. Berkhout, M.T.E. Cornelissen, C.J. Schinkel, K.C.Wolthers. Amsterdam UMC, VUmc site, Amsterdam: HIV treating physicians: E.J.G. Peters ${ }^{\star}$, M.A. van Agtmael,M. Bomers. HIV nurse consultants: M. Heitmuller, L.M. Laan. HIV clinical virologists/chemists: C.W. Ang, R. van Houdt, A.M. Pettersson, C.M.J.E.Vandenbroucke-Grauls. Emma Kinderziekenhuis (AmsterdamUMC): HIV nurse consultants: C. de Boer, A. van der Plas, A.M.Weijsenfeld. Admiraal De Ruyter Ziekenhuis, Goes: HIV treating physicians: M. van den Berge, A. Stegeman. HIV nurse consultants: S. Baas, L. Hage de Looff. HIV clinical virologists/chemists: B Wintermans, J Veenemans . Catharina Ziekenhuis, Eindhoven: HIV treating physicians: M.J.H. Pronk* , H.S.M. Ammerlaan. HIV nurse consultants: E.S. de Munnik. HIV clinicalvirologists/chemists: A.R. Jansz, J. Tjhie, M.C.A. Wegdam, B. Deiman, V. Scharnhorst. DC Klinieken Lairesse - Hiv Focus Centrum: HIV treating physicians: A. van Eeden ${ }^{*}$, M. van der Valk. HIV nurse consultants: W. Brokking, M. Groot, L.J.M. Elsenburg. HIV clinical virologists/chemists: M.Damen, I.S. Kwa. ETZ(Elisabeth-TweeSteden Ziekenhuis), Tilburg: HIV treating physicians: M.E.E. van Kasteren*, A.E. Brouwer. HIV nurse consultants: R. van Erve, B.A.F.M. de Kruijf-van de Wiel, S.Keelan-Pfaf, B. van de Ven. Data collection: B.A.F.M. de Kruijf-van de Wiel, B. van der Ven. HIV clinical virologists/chemists: A.G.M. Buiting, P.J. Kabel, D. Versteeg. Erasmus MC, Rotterdam: HIV treating physicians: M.E. van der Ende*, H.I. Bax, E.C.M. van Gorp, J.L. Nouwen,B.J.A. Rijnders, C.A.M. Schurink, A. Verbon, T.E.M.S. de Vries-Sluijs, N.C. deJong-Peltenburg. HIV nurse consultants: N. Bassant, J.E.A. van Beek, M.Vriesde, L.M. van Zonneveld. Data collection:H.J. van den Berg-Cameron, J. deGroot, M. de Zeeuw-de Man. HIV clinicalvirologists/chemists: C.A.B. Boucher, M.P.G Koopmans, J.J.A van Kampen, S.D.Pas. Erasmus MC-Sophia, Rotterdam: HIV treating physicians: P.L.A. Fraaij, A.M.C. van Rossum, C.L. Vermont . HIV nurse consultants: L.C. van der Knaap, E. Visser. Flevoziekenhuis, Almere: HIV treating physicians: J. Branger ${ }^{\star}$, R.A. Douma. HIV nurse consultant: C.J.H.M. Duijf-van de Ven. HagaZiekenhuis, Den Haag: HIV treating physicians: E.F.

Schippers*, C. van Nieuwkoop. HIV nurse consultants: J.M. van IJperen, J. Geilings. Datacollection: G. van der Hut. HIV clinicalvirologist/chemist: N.D. van Burgel. HMC (Haaglanden Medisch Centrum), Den Haag: HIV treating physicians: E.M.S. Leyten* L.B.S. Gelinck. HIV nurse consultants: S. Davids-Veldhuis, A.Y. van Hartingsveld, C. Meerkerk, G.S. Wildenbeest. HIV clinicalvirologists/chemists: E. Heikens . Isala, Zwolle: HIV treating physicians: P.H.P. Groeneveld*, J.W. Bouwhuis, A.J.J.Lammers . HIV nurseconsultants: S. Kraan, A.G.W. van Hulzen, M.S.M. Kruiper . Datacollection: G.L. van der Bliek, P.C.J. Bor. HIV clinicalvirologists/chemists: P. Bloembergen, M.J.H.M. Wolfhagen, G.J.H.M. Ruijs. Leids Universitair Medisch Centrum, Leiden: HIV treating physicians: F.P. Kroon*, M.G.J. de Boer, H. Scheper, H. Jolink. HIV nurse consultants: W. Dorama, N. van Holten. HIV clinical virologists/chemists: E.C.J. Claas,E. Wessels. Maasstad Ziekenhuis, Rotterdam: HIV treating physicians: J.G. den Hollander*, K. Pogany, A.Roukens. HIV nurse consultants: M. Kastelijns, J.V. Smit, E. Smit, D.Struik-Kalkman, C. Tearno. Data collection: T. van Niekerk. HIV clinicalvirologists/chemists: 0. Pontesilli. Maastricht UMC+, Maastricht: HIV treating physicians: S.H. Lowe*, A.M.L. Oude Lashof, D. Posthouwer. HIV nurse consultants: R.P. Ackens, K. Burgers, J.Schippers. Data collection: B. Weijenberg-Maes. HIV clinical virologists/chemists: I.H.M. van Loo, T.R.A. Havenith. MC Slotervaart, Amsterdam: HIV treating physicians: J.W. Mulder*, S.M.E. Vrouenraets, F.N. Lauw. HIV nurse consultants: M.C. van Broekhuizen, D.J.Vlasblom. HIV clinical virologists/ chemists: P.H.M. Smits. MC Zuiderzee, Lelystad: HIV treating physicians: S. Weijer*, R. El Moussaoui. HIV nurse consultant: A.S. Bosma. Medisch Centrum Leeuwarden, Leeuwarden: HIV treating physicians: M.G.A.van Vonderen*, L.M. Kampschreur. HIV nurse consultants: K. Dijkstra, S. Faber. HIV clinical virologists/chemists: J Weel. Medisch Spectrum Twente, Enschede: HIV treatingphysicians: G.J. Kootstra*, C.E. Delsing. HIV nurse consultants: M. van derBurg-van de Plas, H. Heins. Noordwest Ziekenhuisgroep, Alkmaar: HIV treating physicians: W. Kortmann*, G. van Twillert* R.Renckens . HIV nurse consultant anddata collection: D. Ruiter-Pronk, F.A. vanTruijen-Oud. HIV clinicalvirologists/chemists: J.W.T. Cohen Stuart, E.P. IJzerman, R. Jansen, W. Rozemeijer W. A. van der Reijden. OLVG, Amsterdam: HIV treating 
physicians: K. Brinkman ${ }^{\star}$, G.E.L. van den Berk, W.L. Blok, P.H.J. Frissen, K.D.Lettinga W.E.M. Schouten, J. Veenstra. HIV nurse consultants: C.J. Brouwer, G.F. Geerders, K. Hoeksema, M.J. Kleene, I.B. vander Meché, M. Spelbrink, A.J.M. Toonen, S. Wijnands. HIV clinical virologists: D. Kwa . Data collection: R. Regez (coordinator). Radboudumc, Nijmegen: HIV treating physicians: R. van Crevel*, M.Keuter, A.J.A.M. van der Ven, H.J.M. ter Hofstede, A.S.M. Dofferhoff, S.S.V.Henriet, M. van de Flier, K. van Aerde, J. Hoogerwerf. HIV nurse consultants: M. Albers, K.J.T.Grintjes-Huisman, M. de Haan, M. Marneef, R. Strik-Albers. HIV clinical virologists/chemists: J. Rahamat-Langendoen, F.F. Stelma . HIV clinical pharmacology consultant: D.Burger. Rijnstate, Arnhem: HIV treating physicians: E.H. Gisolf*, R.J. Hassing, M.Claassen. HIV nurse consultants: G. ter Beest, P.H.M. van Bentum, N.Langebeek. HIV clinical virologists/chemists: R. Tiemessen, C.M.A. Swanink. Spaarne Gasthuis, Haarlem: HIV treating physicians: S.F.L. van Lelyveld ${ }^{\star}$, R. Soetekouw. HIV nurse consultants: L.M.M. van der Prijt, J. van der Swaluw. Data collection: N. Bermon. HIV clinical virologists/chemists: W.A. van der Reijden, R. Jansen, B.L. Herpers, D.Veenendaal. Medisch Centrum Janvan Goyen, Amsterdam: HIV treating physicians: D.W.M. Verhagen. HIV nurse consultants: M. van Wijk. Universitair Medisch Centrum Groningen, Groningen: HIV treating physicians: W.F.W. Bierman*, M. Bakker, J. Kleinnijenhuis, E.Kloeze, E.H. Scholvinck, Y.Stienstra, C.L. Vermont, K.R. Wilting, M. Wouthuyzen-Bakker. HIV nurse consultants: A. Boonstra, H. de Groot-de Jonge, P.A. van der Meulen, D.A. de Weerd. HIV clinical virologists/chemists: H.G.M. Niesters, C.C. van Leer-Buter, M. Knoester. Universitair Medisch Centrum Utrecht, Utrecht: HIV treating physicians: A.I.M. Hoepelman*, J.E. Arends, R.E.Barth, A.H.W.Bruns, P.M. Ellerbroek, T. Mudrikova, J.J. Oosterheert, E.M. Schadd, M.W.M. Wassenberg, M.A.D. van Zoelen . HIV nurse consultants: K. Aarsman, D.H.M. van Elst-Laurijssen, I. de Kroon, C.S.A.M. van Rooijen. Data collection: M. van Berkel, C.S.A.M. van Rooijen. HIV clinical virologists/chemists: R. Schuurman, F. Verduyn-Lunel, A.M.J. Wensing Wilhelmina Kinderziekenhuis, UMC Utrecht,Utrecht: HIV treating physicians: L.J. Bont, S.P.M. Geelen, T.F.W.Wolfs. HIV nurse consultants: N. Nauta. COORDINATING CENTRE Director: P Reiss. Deputy director: S Zaheri. Data analysis: D 0 Bezemer, A I van Sighem, C Smit, FW M N Wit and T S Boender. Data management and quality control: M Hillebregt, A de Jong and T Woudstra. Data monitoring: D Bergsma, S Grivell, R Meijering, M Raethke and T Rutkens. Data collection: $L$ de Groot, $M$ van den Akker, Y Bakker, M Bezemer, E Claessen, A El Berkaoui, J Geerlinks, J Koops, E Kruijne, C Lodewijk, E Lucas, R van der Meer, L Munjishvili, F Paling, B Peeck, C Ree, R Regtop, Y Ruijs, M Schoorl, E Tuijn, L Veenenberg, S van der Vliet, A Wisse and E C Witte. Patient registration: B Tuk.

Contributors TSB wrote the first draft of the manuscript. AvS, CJS, FWNMW and TSB performed the analyses for the key statistics, tables and figures of the cohort. PR provided overall supervision of the cohort profile. All authors contributed to interpreting the data and to the writing and revising of the manuscript.

Funding The ATHENA cohort is managed by Stichting HIV Monitoring and supported by a grant from the Dutch Ministry of Health, Welfare and Sport through the Centre for Infectious Disease Control of the National Institute for Public Health and the Environment.

Competing interests None declared.

Patient consent Not required.

Ethics approval At initiation, the cohort was approved by the institutional review board of all participating centres. People entering HIV care receive written material about participation in the ATHENA cohort and are being informed by their treating physician of the purpose of collection of data, after which they can consent verbally or elect to opt-out. Data are pseudonymised before being provided to investigators and may be used for scientific purposes. A designated quality management coordinator safeguards compliance with the European General Data Protection Regulation.

Provenance and peer review Not commissioned; externally peer reviewed.

Data sharing statement HIV physicians can review the data of their own treatment centre and compare these data with the full cohort through an online report builder. Statistical information or data for own research purposes can be requested by submitting a research proposal (https://www.hiv-monitoring.nl/ english/research/research-projects/). For correspondence: hiv.monitoring@amc. uva.nl.

Open access This is an open access article distributed in accordance with the Creative Commons Attribution Non Commercial (CC BY-NC 4.0) license, which permits others to distribute, remix, adapt, build upon this work non-commercially, and license their derivative works on different terms, provided the original work is properly cited, appropriate credit is given, any changes made indicated, and the use is non-commercial. See: http://creativecommons.org/licenses/by-nc/4.0/.

\section{REFERENCES}

1. Stichting HIV Monitoring. ATHENA report 2001. Stichting HIV Monitoring, 2001. www.hiv-monitoring.nl.

2. van Sighem Al, Boender TS, Wit F, et al. Monitoring report 2017. Human immunodeficiency virus (hiv) infection in the Netherlands. Amsterdam. 2017 wwww.hiv-monitoring.nl.

3. Hermanides HS, Gras L, Winkel CN, et al. The efficacy of combination antiretroviral therapy in HIV type 1-infected patients treated in Curaçao compared with Antillean, Surinam, and Dutch HIV type 1-infected patients treated in The Netherlands. AIDS Res Hum Retroviruses 2011;27:605-12.

4. Stichting HIV Monitoring. Jaarverslag 2016. Amsterdam: Stichting HIV Monitoring, 2017.

5. Europese Unie. Regulation (EU) $2016 / 679$ of the European parliament and of the council. Off J Eur Union 20162016;4-.

6. European Centre for Disease Prevention and Control. WHO regional office for europe. HIV/AIDS surveiliance in Europe 2015. Stockholm.2016.

7. Stichting HIV Monitoring. Complete overview of data collected by SHM. https://www.hiv-monitoring.nl/english/medical-professionals/ patient-data-collection/.

8. Centers for Disease Control and Prevention. Revised classification system for HIV infection and expanded surveillance case definition for AIDS among adolescents and adults. MMWR 1993;1992:1-19.

9. Kowalska JD, Friis-Møller N, Kirk O, et al. The Coding Causes of Death in HIV (CoDe) Project: initial results and evaluation of methodology. Epidemiology 2011;22:516-23.

10. Antinori A, Coenen T, Costagiola D, et al. Late presentation of HIV infection: a consensus definition. HIV Med 2011;12:61-4.

11. Op de Coul EL, van Sighem A, Brinkman K, et al. Factors associated with presenting late or with advanced HIV disease in the Netherlands, 1996-2014: results from a national observational cohort. BMJ Open 2016;6:e009688.

12. European Centre for Disease Prevention and Control. ECDC HIV Modelling Tool [software application]. Version 1.2. European Centre for Disease Prevention and Control: Stockholm, 2016.

13. Sasse A, Florence E, Pharris A, et al. Late presentation to HIV testing is overestimated when based on the consensus definition. HIV Med 2016;17:231-4.

14. Ratmann O, van Sighem A, Bezemer D, et al. Sources of HIV infection among men having sex with men and implications for prevention. Sci Trans/ Med 2016;8:320ra2.

15. Gras L, Jurriaans $\mathrm{S}$, Bakker M, et al. Viral load levels measured at set-point have risen over the last decade of the HIV epidemic in the Netherlands. PLoS One 2009;4:e7365.

16. Gras L, de Wolf F, Smit C, et al. Changes in HIV RNA and CD4 cell count after acute HCV infection in chronically HIV-infected individuals. J Acquir Immune Defic Syndr 2015;68:536-42.

17. Gras L, Kesselring AM, Griffin JT, et al. CD4 cell counts of 800 cells/ $\mathrm{mm} 3$ or greater after 7 years of highly active antiretroviral therapy are feasible in most patients starting with 350 cells $/ \mathrm{mm} 3$ or greater. $J$ Acquir Immune Defic Syndr 2007;45:183-92.

18. Bezemer D, de Wolf F, Boerlijst MC, et al. 27 years of the HIV epidemic amongst men having sex with men in the Netherlands: an in depth mathematical model-based analysis. Epidemics 2010;2:66-79.

19. van Sighem A, Bezemer D, Op de Coul E, et al, 2017. Earlier diagnosis and treatment reduces HIV transmisison in MSM in the Netherlands. Conference on Retroviruses and Opportunistic Infections (CROI) 1041. http://www.croiconference.org/sessions/ earlier-diagnosis-and-treatment-reduces-hiv-transmission-msmnetherlands

20. Bezemer D, van Sighem A, Lukashov VV, et al. Transmission networks of HIV-1 among men having sex with men in the Netherlands. AIDS 2010;24:271-82.

21. Hofstra LM, Sauvageot N, Albert J, et al. Transmission of HIV Drug Resistance and the Predicted Effect on Current First-line Regimens in Europe. Clin Infect Dis 2016;62:655-63.

22. van Sighem Al, van de Wiel MA, Ghani AC, et al. Mortality and progression to AIDS after starting highly active antiretroviral therapy. AIDS 2003;17:2227-36.

23. van Sighem Al, Gras LA, Reiss P, et al. Life expectancy of recently diagnosed asymptomatic HIV-infected patients approaches that of uninfected individuals. AIDS 2010;24:1527-35.

24. Verbond van Verzekeraars [Dutch Association of Insurers]. HIV Insurability Expanded - Report of the HIV Working Group. 2009 http://www.hivnet.org/downloads/pdf/verzekerbaarheid_hiv _ uitgebreid_eng_juni2009.pdf.

25. Smit M, Brinkman K, Geerlings S, et al. Future challenges for clinical care of an ageing population infected with HIV: a modelling study. Lancet Infect Dis 2015;15:810-8. 
26. Smit M, van Zoest RA, Nichols BE, et al. Cardiovascular Disease Prevention Policy in Human Immunodeficiency Virus: Recommendations From a Modeling Study. Clin Infect Dis 2018;66:743-50.

27. UNAIDS. (Joint United Nations Programme on HIV/AIDS). 90-90-90 - An ambitious treatment target to help end the AIDS epidemic. 2014 http://www.unaids.org/en/resources/documents/2014/90-90-90.

28. Joint United Programme on HIV/AIDS (UNAIDS). Ending AIDS: Progress towards the 90-90-90 targets. 2017 http://www.unaids.org/ sites/default/files/media asset/Global AIDS update_2017 en.pdf.

29. van Sighem A, Op de Coul E, Boender TS, et al. From HIV infection to HIV suppression: improvements in the time to reach successive stages in the HIV care continuum in the Netherlands. Paris: IAS Science Paris, 2017.

30. Cohen S, Smit C, van Rossum AM, et al. Long-term response to combination antiretroviral therapy in HIV-infected children in the Netherlands registered from 1996 to 2012. AIDS 2013;27:2567-75.

31. Weijsenfeld AM, Smit C, Cohen S, et al. Virological and social outcomes of hiv-infected adolescents and young adults in the Netherlands before and after transition to adult care. Clin Infect Dis 2016:63:1105-12.

32. Vanhommerig JW, Bezemer D, Molenkamp R, et al. Limited overlap between phylogenetic HIV and hepatitis $\mathrm{C}$ virus clusters illustrates the dynamic sexual network structure of Dutch HIV-infected MSM. AIDS 2017;31:2147-58.

33. Boerekamps A, Newsum AM, Smit C, et al. High Treatment Uptake in Human Immunodeficiency Virus/Hepatitis C Virus-Coinfected Patients After Unrestricted Access to Direct-Acting Antivirals in the Netherlands. Clin Infect Dis 2018;66:1352-9.

34. Hillebregt M, de Lange-de Klerk E, Knol D, et al. Measuring the Quality of Data Collection in a Large Observational Cohort of HIV and AIDS. Open AIDS J 2010;4:96-102.

35. Nederlandse Federatie van Universitair Medische Centra. Indicatorgids HIV-AIDS 2014. Thema Zichtbare zorg. 2014 http:// www.nfu.nl/thema/zichtbare-zorg/ (accessed 20 Nov 2017).

36. Jansen IA, Geskus RB, Davidovich U, et al. Ongoing HIV-1 transmission among men who have sex with men in Amsterdam: a 25-year prospective cohort study. AIDS 2011;25:493-501.

37. van Zoest RA, Wit FW, Kooij KW, et al. Higher prevalence of hypertension in hiv-1-infected patients on combination antiretroviral therapy is associated with changes in body composition and prior stavudine exposure. Clin Infect Dis 2016;63:205-13.

38. Underwood J, Cole JH, Caan M, et al. Gray and white matter abnormalities in treated human immunodeficiency virus disease and their relationship to cognitive function. Clin Infect Dis 2017;65:422-32.

39. Hoornenborg E, Prins M, Achterbergh RCA, et al. Acquisition of wildtype HIV-1 infection in a patient on pre-exposure prophylaxis with high intracellular concentrations of tenofovir diphosphate : a case report. Lancet HIV 2017;3018:1-7.

40. Chêne G, Phillips A, Costagliola D, et al. Cohort profile: Collaboration of Observational HIV Epidemiological Research Europe (COHERE) in EuroCoord. Int J Epidemiol 2017;46:797.

41. Schultze A, Phillips AN, Paredes $R$, et al. HIV resistance testing and detected drug resistance in Europe. AIDS 2015;29:1379-89.

42. Ngo-Giang-Huong N, Wittkop L, Judd A, et al. Prevalence and effect of pre-treatment drug resistance on the virological response to antiretroviral treatment initiated in HIV-infected children - a EuroCoord-CHAIN-EPPICC joint project. BMC Infect Dis 2016;16:654

43. Benard A, van Sighem A, Taieb A, et al. Immunovirological response to triple nucleotide reverse-transcriptase inhibitors and ritonavirboosted protease inhibitors in treatment-naive HIV-2-infected patients: The ACHIEV2E Collaboration Study Group. Clin Infect Dis 2011;52:1257-66.

44. May MT, Ingle SM, Costagliola D, et al. Cohort profile: Antiretroviral Therapy Cohort Collaboration (ART-CC). Int J Epidemiol 2014;43:691-702.

45. Smith CJ, Ryom L, Weber R, et al. Trends in underlying causes of death in people with HIV from 1999 to 2011 (D:A:D): a multicohort collaboration. Lancet 2014;384:241-8.

46. Lodi S, Günthard HF, Dunn D, et al. Effect of immediate initiation of antiretroviral treatment on the risk of acquired HIV drug resistance. AIDS 2018;32:1.

47. Cornelissen $M$, Gall $A$, Vink $M$, et al. From clinical sample to complete genome: Comparing methods for the extraction of HIV-1 RNA for high-throughput deep sequencing. Virus Res 2017;239:10-16.

48. Revell AD, Wang D, Wood R, et al. An update to the HIV-TRePS system: the development of new computational models that do not require a genotype to predict HIV treatment outcomes. J Antimicrob Chemother 2014;69:1104-10.

49. Revell A, Khabo P, Ledwaba L, et al. Computational models as predictors of HIV treatment outcomes for the Phidisa cohort in South Africa. South Afr J HIV Med 2016;17:1-7.

50. Avila D, Althoff KN, Mugglin C, et al. Immunodeficiency at the start of combination antiretroviral therapy in low-, middle-, and high-income countries. J Acquir Immune Defic Syndr 2014;65:e8-16. 